\title{
Delayed Access to Medical Care of Patients with Breast Cancer
}

\author{
Retraso en la atención médica de los pacientes con cáncer de mama
}

\author{
Kenia Yazmín García Perusquía, Juan Carlos Paz Bautista \\ Área Académica de Medicina del Instituto de Ciencias de la Salud \\ Universidad Autónoma del Estado de Hidalgo, México. \\ Corresponding Author: Kenya Yazmin Garcia Perusquía, Instituto de Ciencias de la Salud, Ex Hacienda La Concepción s/n \\ Carretera Pachuca-Actopan Tilcuautla, Hidalgo, México. Tel. 7713342769, E-mail: kenia_garciap@hotmail.com
}

\begin{abstract}
:
Breast cancer is a public health problem and it is more frequent in women living in both developed and developing countries, so it is important to identify the factors associated with delayed access to health care and to implement public policies for a timely diagnosis and treatment. The objective of this review is to collect existing information on breast cancer, its definition, classification, and to identify socio-structural factors of health care services that are associated with delayed medical care that negatively affects in clinical nationalization and therefore a 5-year survival, besides the need for further research related to this topic. Timely diagnosis and therapy for patients with breast cancer require the modification and implementation of current public policies in order to contribute to the reduction of mortality, especially in developing countries, since it has not only an economic impact but also a personal, social and family impact. Late diagnosis and treatment of breast cancer have been associated with a reduced survival period due to the clinical stage of the diagnosis in which a delay of more than three months was identified related to delays in the patient and not only by the lack of identification of signs and symptoms, but also by the lack of human resources and infrastructure.
\end{abstract}

Key words:

Breast cancer, Delayed care, Survival, Prognosis

\section{Resumen:}

El cáncer de mama es un problema de salud pública y más frecuente en mujeres de tanto en países desarrollados como en vías de desarrollo por lo que es importante identificar los factores asociados al retraso en la atención e implementar políticas públicas para el diagnóstico y tratamiento oportunos. El objetivo de esta revisión es el poder recopilar información existente acerca del cáncer de mama, definición, clasificación e identificar los factores socio-estructurales y de los servicios de salud que estén asociados en el retraso de la atención médica que impacta de manera negativa en la estatificación clínica y por ende en la supervivencia a 5 años, además de la necesidad de realizar mayor investigación relacionado a este tema. La oportunidad diagnóstica y terapéutica de pacientes con cáncer de mama requiere de modificación e implementación de políticas públicas actuales con la finalidad de contribuir a la disminución de la mortalidad sobre todo en países en desarrollo, ya que tiene no solo el impacto económico sino también en lo personal, social y familiar. El diagnóstico y tratamiento tardíos del cáncer de mama se asociaron con un tiempo de supervivencia reducido debido a la etapa clínica del diagnóstico en el que se identificó un retraso de más de tres meses relacionado con los retrasos en el paciente y no solo por la falta de identificación de signos y síntomas, pero también por falta de recursos humanos e infraestructura.

\section{Palabras Clave:}

Cáncer de mama, retraso en la atención, supervivencia, pronóstico

\section{Introduction}

Breast cancer is a disease due to the abnormal and disorganized growth of epithelial cells in the breast ducts and lobules that has the capacity to spread. It has several causative agents such as genetic, familial and behavioral agents. The World Health Organization (WHO) considers this disease a public health problem and the most frequent cancer in women living in developed and developing countries; although mortality in developed countries had decreased due to timely detection and effective treatment. ${ }^{1}$

The delay in the diagnosis and treatment of breast cancer is not only associated with a reduced survival period, meaning that, the longer the delay, the higher the probability of the tumor being bigger, in addition to the lymph node impact, which leads to more aggressive treatments, so women may require mastectomy instead of conservative surgery, as well as a more toxic or extended adjuvant treatment. Some studies report that 
patients diagnosed with an advanced disease have also shown having significant psychological morbidity, which influences the patient's quality of life. ${ }^{2}$

Delayed care of patients with breast cancer is due to the delayed care on behalf of the patient and the provider. That is any delay between the discovery of symptoms and the first medical consultation is considered the responsibility of the patient, and the health system or supplier is responsible for the interval between the first medical consultation and the beginning of the cancer treatment. ${ }^{3}$ As well as total delay, the patient's delay longer than 3 months is associated with an advanced stage cancer and a reduced survival. The impact of delayed health care system on patient's prognosis is more unclear because there are few studies about this topic, besides there is a lot of variability in the intervals' measurements which limits the power to make the comparison. ${ }^{3}$

\section{Epidemiology of breast cancer}

Breast cancer is the most common malignant tumor in women around the world, information on the incidence and mortality of breast cancer is essential for planning health care measures. ${ }^{4}$ According to data from the International Association of Cancer Registries, 1,671,149 new cases of breast cancer and 521,907 deaths have been identified around the world in 2012, this being the most common cancer in women, representing $25.1 \%$ of all cancers. The incidence rate of breast cancer varies from 19.4 per 100,000 people in East Africa to 89.7 per 100,000 in Western Europe. ${ }^{4}$

The importance of breast cancer can be due to risk factors such as unhealthy lifestyles, long-term fertility that occurs in menarche in early ages and menopause in advanced ages, the use of hormones of pregnancy and not having children, obesity after menopause, the use of hormone replacement therapy, physical inactivity and alcohol as risk factors. ${ }^{4}$

Breast cancer is increasing in South America, Africa and Asia. Some researches show that early detection of breast cancer has an important role in reducing the mortality rate and improving the prognosis of the disease. According to the International Agency for Research on Cancer (IARC), the incidence rate was estimated in 1,671,149 new cases of breast cancer by 2012 , 882.9 per 100,000 were attributed to less developed countries, while 793.7 (per 100,000) were attributed to developed countries, being the most common cancer in women with a standardized incidence rate of 43.1 per $100,000 .^{4}$

Among the six WHO regions, it was observed an incidence rate of 67.6 in the Pan American Health Organization (PAHO) and the lowest one of 27.8 in South East Asia Region (SEARO), the highest incidence rate of 111.9 in Belgium and the lowest one of 9 in Mongolia and Lesotho. Five countries with the highest standardized incidence rate per 100,000 were Belgium 111.9, Denmark 105, Bahamas 98 and the Netherlands 96. According to the division of the continents, the highest incidence rates were 91.6 and 91.1 for North America and Western Europe, respectively. However, the lowest incidence rates were 26.8 and 27 in Middle Africa and East Asia, respectively. Regarding the mortality rate, it was estimated that 521,907 of deaths around the world were because of breast cancer in 2012. Five countries with the highest standardized mortality rate (per 100,000) were Fiji (28.4), Bahamas (26.3), Nigeria 25.9), FYR Macedonia (25.6) and Pakistan (25.2). ${ }^{4}$

Mortality in lower-income countries is higher. Women in lowincome countries, especially in Africa (Kenya and Uganda) are seeking advanced disease treatments when it has spread to other organs and is associated with increased morality unlike England and Australia where very few women are diagnosed in stages III and IV of the disease. It is important to mention that in Mexico and South America, women are diagnosed in stages II or III of the disease, but the risk of death is due to other reasons. Some studies show that survival depends on the timing of diagnosis and the access to the treatment. ${ }^{4}$ In México, in the year 2015 there were 6,252 deaths in women with a gross rate of 18 deaths per 100,000 women. The entities with the highest mortality due to breast cancer were: Sonora (28.6), Nuevo León (26), Coahuila (25.7), Chihuahua (24.8), Mexico City (24.7) and Sinaloa (22.2). ${ }^{5}$

In 2005, it is estimated that 1,690 new cases of male breast cancer will be diagnosed in the United States (U.S.), and 460 men will die as a result of breast cancer. Male breast cancer represents only $0.7 \%$ of all breast cancer diagnoses, the average age at the moment of diagnosis for men with breast cancer is 67 years old, which is 5 years higher than the average age at the moment of diagnosis for women. ${ }^{6}$

For the U.S., 246,660 new diagnoses and 40,450 deaths have been visualized for 2016, although a large majority will be diagnosed with breast cancer in situ, $6 \%$ will have metastasis and between $10 \%$ and $40 \%$ will suffer from relapses. ${ }^{7}$

This type of cancer has also emerged as the leading cause of morbidity and mortality in European populations and it has been estimated that $10 \%$ to $12 \%$ of women will develop breast cancer in the course of their lives. ${ }^{8}$

In Latin America, breast cancer is the first most common neoplasm in women in Latin America, with an incidence of 152,059 cases per year. The incidence in the region is 27 cases per 100,000 women, reaching values higher than 50 in countries like Argentina, Uruguay, Brazil and Guyana, the mortality in the region is 43,208 deaths with a rate of 47.2 per 100,000 women, this represents $14 \%$ of the annual deaths due to this cause. ${ }^{9}$

\section{Breast Cancer as a Public Health Problem}

Breast cancer is a disease in which malignant cells develop in the tissues of the mammary glands that are made up of lobes and lobules connected by multiple ducts, which can be affected unilaterally or bilaterally. ${ }^{10}$

A breast cancer cell usually doubles every $100-300$ days, so a 1 $\mathrm{cm}$ breast neoplasm had to do about 30 doublings before reaching that size, so it is assumed that this cancer has at least 7 years of evolution. This simple estimation suggests the importance of early detection, with methods capable of visualizing subclinical abnormalities smaller than one centimeter. $^{10}$

Breast cancer is the most common in women in developed and developing regions, but mortality rates are lower in developed countries and survival is more favorable in these countries. ${ }^{11}$

\section{Breast Cancer Staging System}

The stage of a cancer at the time of the diagnosis is a key factor that is used to define the treatment and to be able to evaluate the probability of its success. Cancer staging systems encode the magnitude that is important to provide clinicians and patients with prognosis. This classification is based on tumor size (T), dissemination or no dissemination to lymph nodes $(\mathrm{N})$ and 
metastasis or no metastasis to other organs $(\mathrm{M}) .{ }^{11}$ there are three stratification systems used in the United States ${ }^{12}$ :

1. State cancer registries used for population incidence and surveillance. They use the relatively simple summary statistics system.

2. The National Cancer Institute's Surveillance, Epidemiology, and End Results (SEER) program, which developed its own "extent of disease" system.

3. The most widely used stratification system among clinicians is the TNM system maintained by the American Joint Committee on Cancer (AJCC) and the Union for International Cancer Control (UICC). It should be noted that this system encodes the extent of the primary tumor $(\mathrm{T})$, the regional lymph nodes (N)and distant metastasis (M) and provides a clustering in $\mathrm{T}, \mathrm{N}$, and $\mathrm{M}$, presented at the $7^{\text {th }}$ edition of the American Joint Committee on Cancer (AJCC). ${ }^{12}$

In the $8^{\text {th }}$ edition of the American Joint Committee on Cancer Manual, they challenge the relevance of TNM stratification system purely for breast cancer, so it is important to compress biological tumor markers such as the estrogen receptor (ER), progesterone receptor (PR) and the human epidermal growth factor receptor (HER2) and their impact on prognosis. While it is true that the panel acknowledged the clinical utility of these biological factors which have become as important as the extent of the disease to predict survival, in addition to the selection of breast cancer therapy, this panel of experts also recognizes that a big part of the world does not have access to reliable analysis, so continuing with the use of TNM anatomical staging provides continuity with the past and allows breast cancer researchers to compare groups of patients who were treated at different times and that this staging allows researchers to communicate around the world using a standardized language that reflects the tumor burden. ${ }^{12-14}$

\section{Delay in breast cancer medical care}

The prognosis of the disease is determined, among other factors, by the time between onset of the condition and timely access to integral treatment. Some researchers have studied how delays in the access to diagnosis and treatment can be socially determined, with higher percentage of negative results among the most vulnerable population. ${ }^{15}$

Primary care providers have a fundamental role in the process of health care from the moment of detection and diagnosis to the moment of health care delivery during and after treatment. There is evidence that shows that the highest rates of participation in detection are in primary care, they are important to reduce the delay in diagnosis, particularly because the health system itself has long waiting times. ${ }^{16}$

Long delays are associated with prognosis deterioration, reduced survival rates, and higher incidence of mastectomy. Several researches have examined delays in the diagnosis and treatment of breast cancer; however, few researches have analyzed in detail how the delay with the patient and specific factors of the system, so it is important to investigate what factors influence the patient and the delay of the system. ${ }^{17}$

Delayed breast cancer health care, defined as more than 3 months from the discovery of symptoms by the patient to the beginning of definitive treatment, is associated with an advanced stage of the disease at presentation and with a reduced probability of survival. ${ }^{18}$
This delay in health care is subdivided into two groups:

1. The patient's delay, which is defined as an interval between the date when the first symptom appeared, that is, the date when the first physical change was detected and the first medical appointment, this is the date when the patient visits the clinician for revision, and ideally this date should not be more than 3 months. ${ }^{18,19}$

2. The delay of the provider, considered between the first medical consultation and the beginning of the treatment, which should not be longer than one month. ${ }^{18,19}$

The objective of identifying the main causes of delays in health care is to be able to identify opportunities to introduce strategies aimed at reducing periods of attention, by an early detection and the implementation of relevant and timely treatments. This would lead us to increase the survival rate to 5 years. ${ }^{20}$

There are some studies that try to identify the factors associated with the late diagnosis and the start of the treatment of breast cancer patients. A research conducted in Turkey investigated the two periods of delayed health care and one of the factors that were found is suspicion concerning the health care system, the exploration of the breasts and the low educational level. ${ }^{17}$

In Mexico, a cross sectional study was conducted with 886 patients who were referred to four public hospitals, data were collected on time intervals, socio-demographic factors and clinical stage at the time of diagnosis, finding an average time of attention from the identification of the problem to the beginning of a seven-month treatment and only $15 \%$ of them were diagnosed with the disease at stages 0 and I, and $48 \%$ were diagnosed with stages III and IV. Multivariate analyzes confirmed independent correlations to identify the problem, the patient's delay, health care system delay, and age, with a higher probability that patients would begin cancer treatment at an advanced stage, and finally it is concluded that both delays in patients and suppliers were associated with an advanced disease. $^{3}$

A study was conducted in two public hospitals in the city of Rosario, province of Santa Fe, Argentina, to identify the delays of health care in patients with breast cancer. The objective of this study was to describe the trajectory of breast cancer patients from the moment of appearance of a sign or symptom until the end of the treatment. It defined four health care moments, including 62 patients. The study was analyzed and it allowed observing delays in all stages of the health care process, particularly in women with diagnoses in more advanced stages (III and IV). ${ }^{20}$

At the Institute of Nuclear Medicine, Oncology and Radiotherapy in Islamabad, Pakistan, a cross-sectional study was conducted from September 2012 to August 2013, where 315 patients were histologically confirmed with breast cancer and it defined as delayed health care of more than 3 months after the appearance of symptoms at the consultation with the medical expert. Some of the factors associated with this delay were less than 8 years of schooling and a low socioeconomic status. A percentage of $39.01 \%(n=123)$ of patients were delayed and among them, $40.7 \%$ wasted time using alternative medicines; $25.2 \%$ did not have enough resources; $17.1 \%$ were delayed due to a painless lump; $10.6 \%$ felt shy and $6.5 \%$ were delayed because of other non-specified reasons. ${ }^{21}$

A cohort study was performed with women that were treated at two radiation oncology centers in the province of Quebec, Canada, from September 15, 2002 to October 26, 2003, to 
identify the determinants of diagnosis delay with the purpose of developing strategies to reduce the waiting time of breast cancer diagnosis. In this study, a cohort of 696 women diagnosed with early breast cancer at two radiation oncology centers was recruited. A structured questionnaire was administered to identify possible determinants of the diagnosis delay. The "diagnosis delay" was defined as an interval of more than 5 weeks from the first specific breast procedure and the final diagnostic procedure. The obtained results were the medical indication for breast research and the programming of diagnostic procedures. The diagnosis delay was also significantly associated with the interpretation of the first diagnostic procedure, the type of final diagnostic procedure, tumor size and family income. ${ }^{16}$

\section{Conclusions}

Breast cancer is considered a public health problem because of its high incidence and mortality rate in developing countries, not just because a bad lifestyle and modifiable and unmodifiable risk factors such as age, early menarche, late menopause, alcohol, among others, but also has to do with the health care process. Therefore, it is important to do more research on which are the main factors associated with this delay in patients' diagnosis, and once these factors are identified, it is necessary to implement strategies to improve public health care.

\section{References}

Ministerio de Salud. Subsecretaria de Salud Pública. Guías Clínicas AUGE. Cáncer de Mama. Chile: División de Prevención y Control de Enfermedades. Departamento Manejo Integral del Cáncer y otros tumores; 2015: 1-164.

Unger-Saldaña K, Infante-Castañeda C. Delay of medical care for symptomatic breast cancer: A literature review. Salud Pub. Mex. 2009; 51(suppl 2): S270-S285.

Unger-Saldaña K, Miranda A, Zarco-Espinosa G, Mainero-Ratchelous F, Bargalló-Rocha E, Miguel Lázaro-León J. Health system delay and its effect on clinical stage of breast: Multicenter study. Cancer 2015; 121: 2198-206.

Ghoncheh M, Pournamdar Z, Salehiniya H. Incidence and Mortality and Epidemiology of Breast Cancer in the World. Asian Pac. J. Cancer Prev. 2016; 17: 43-46.

Centro Nacional de Equidad de Género y Salud Reproductiva [página en internet]. México. Prevención y control de cáncer en la Mujer. Información estadística. Available from: http://cnegsr.salud.gob.mx/contenidos/Programas_de_Accion/Cancerd elaMujer/InfEstad.html

Giordano SH. A review of the diagnosis and management of male breast cancer. Oncologist 2005; 10: 471-479.

Zeichner S, Terawaki H, Gogineni K. A Review of Systemic Treatment in Metastatic Triple-Negative Breast Cancer. Breast Cancer (Auckl). 2016; 10: 25-36.

Kleibl Z, Kristensen V. Women at high risk of breast cancer: Molecular characteristics, clinical presentation and management. The Breast 2016; 28: 136-144.

Centro Nacional de Equidad de Género y Salud Reproductiva [homepage on the Internet]. México: Información Estadística; c 2000-2015. Available from: http://cnegsr.salud.gob.mx/contenidos/Programas_de_Accion/Cancerd elaMujer/InfEstad.html

Brandan ME, Villaseñor-Navarro Y. Detección del cáncer de mama: Estado de la Mamografía en México. Cancerología 2006; 1: 147-162.

Martínez M. El acceso al continuo de servicios entre niveles asistenciales en dos redes integradas de servicios de salud en Colombia: un estudio de casos múltiples de mujeres con cáncer de mama. Rev. Fac. Nac. Salud Pública 2012; 30: 86-89.
Edge SB, Compton CC. The American Joint Committee on Cancer: the 7th Edition of the AJCC cancer staging manual and the future of TNM. Ann. Surg. Oncol. 2010; 17: 1471-1474.

Connolly LJ, Stephen BE, Mittendorf EA, et al. Breast Cancer-Major changes in the American Joint Committee on Cancer eighth edition cancer staging manual. CA. Cancer. J. Clin. 2017; 67: 290-303.

American Cancer Society [homepage on the Internet] 2017. Tasas de supervivencia del cáncer de seno. Atlanta, Georgia, Estados Unidos [Last Medical Review: June 1, 2016] [Last Revised: August 18, 2016]. Available from: https://www.cancer.org/es/cancer/cancer-deseno/comprension-de-un-diagnostico-de-cancer-de-seno/tasas-desupervivencia-del-cancer-de-seno.html.

Sánchez G, Niño CG, Estupiñán C. Factores asociados con el tratamiento oportuno de mujeres con cáncer de mama apoyadas por una organización no gubernamental en Bogotá. Biomédica. 2015; 35: 505512.

Jon DE, Shaw K, Williams B, et al. The role of primary care in early detection and follow-up of cancer. Nat. Rev. Clin. Oncol. 2014; 11 : 38-48.

Vahit O, Boylu S, Ok E, et al. Factors affecting breast cancer treatment delay in Turkey: a study from Turkish Federation of Breast Diseases Societies. Eur. J. Public. Health. 2015; 25: 9-14.

Unger-Saldaña K, Infante-Castañeda CB. Breast cancer delay: a grounded model of help-seeking behaviour. Soc. Sci. Med. 2011; 72: 1096-104.

Weller D, Vedsted P, Rubin G, et al. The Aarhus statement: improving design and reporting of studies on early cancer diagnosis. Br. J. Cancer 2012; 106: 1262-7.

Mignini L, Ramos S, Pesce V, et al. Demoras en el proceso de atención de pacientes con cáncer de mama en dos hospitales públicos de la provincia de Santa Fe. Rev. Argent. Salud Pública, 2016; 7: 21-26.

Khan MA, Hanif S, Igbal S, Shahzad MF, Shafique S, Khan MT. Presentation delay in breast cancer patients and its association with sociodemographic factors in North Pakistan. Chin. J. Cancer Res. 2015; 27: 288-293. 